\title{
Radiation Field Preference for Radiographic Anatomical Markers by Radiographers in a University Teaching Hospital in Nigeria
}

\author{
Thomas Adejoh ${ }^{1 *}$, Sobechukwu Warric Iwene Onwuzu2 ${ }^{2}$, Flavious Bobuin Nkubli³, \\ Nwamaka Ikegwuonu ${ }^{1}$ \\ ${ }^{1}$ Radiology Department, Nnamdi Azikiwe University Teaching Hospital, Nnewi, Nigeria \\ ${ }^{2}$ Medical Imaging Unit, Department of Medical Centre, University of Nigeria, Nsukka, Nigeria \\ ${ }^{3}$ Department of Medical Radiography, College of Medical Sciences, University of Maiduguri, Maiduguri, Nigeria \\ Email: adtoms@yahoo.com, warric85@yahoo.com, activeflavour@yahoo.com, \\ ikegwuonunwamaka@gmail.com
}

Received 5 August 2014; revised 7 September 2014; accepted 17 September 2014

Copyright (C) 2014 by authors and Scientific Research Publishing Inc.

This work is licensed under the Creative Commons Attribution International License (CC BY). http://creativecommons.org/licenses/by/4.0/

c) (i) Open Access

\begin{abstract}
Objective: The work aims to determine the radiographers' preference between primary and secondary radiation fields for imprinting anatomical markers on radiographs. Methodology: Processed radiographs from the darkroom with evidence of radiographic anatomical markings were selected randomly and reviewed using a viewing box, within a 4-week period. The radiation field in which markers were placed was noted for each radiograph. Faintly-appearing and partly conedoff markers were excluded. Simple statistical tools were used to derive central tendency. Result: 623 radiographs were assessed. $89.0 \%(n=555)$ had markers in the primary radiation field while $11.0 \%(n=68)$ were in the secondary radiation field. $98 \%(n=611)$ of markers did not obstruct essential anatomy while $2 \%(n=12)$ did, but the radiographs were neither repeated nor rejected because of the twin reason of reportability and the need to avoid additional radiation dose to patients. Conclusion: Radiographers in the centre preferred the primary radiation field for marker placement to avoid cone-off, cut-off and illegibility which leads to repeat. This, however, does not offer superior advantage to markers placed in secondary radiation field. It is recommended that marker placement preference should be guided by the need for legibility, aesthetics and avoidance of essential anatomy.
\end{abstract}

\section{Keywords}

Marker, Radiation Field, Radiographs, Radiographers

${ }^{*}$ Corresponding author.

How to cite this paper: Adejoh, T., Onwuzu, S.W.I., Nkubli, F.B. and Ikegwuonu, N. (2014) Radiation Field Preference for Radiographic Anatomical Markers by Radiographers in a University Teaching Hospital in Nigeria. Open Journal of Radiology, 4, 275-278. http://dx.doi.org/10.4236/ojrad.2014.43036 


\section{Introduction}

Left-side and right-side indicator markers are identified as one of the most common sources of error in radiography [1]. These anatomical markers are portable metallic objects curved in the shape of a letter " $U$ " with a void capital "L" and "R" carved on each alternate ramus. A team of researchers noted that in forensic radiography, radiographic markers must be included on the image in order to be regarded as a legal document [2].

Improperly-identified films result in confusion, wasted time and effort, increased cost and perhaps, unnecessary radiation to the patient [3]. It is advocated that radiopaque markers should be within the collimation field and should not cover essential anatomy [4]. However, in a work carried out in East Anglia, the authors concluded that there was a conflict of opinion about the necessity for anatomical side markers to be used within the primary beam [5].

The radiographers in our centre are university-trained and have one to twelve years' post-graduation experience. What is their radiation field preference for marker placement and why?

\section{Materials and Methods}

A sample size of 398 radiographs was determined by formula from a population of 11,000 radiographs produced in 2013. 56.5\% $(n=225)$ was added to improve accuracy thereby bringing the total to 623 radiographs. The researchers, over a period of four weeks, randomly selected radiographs with distinct radiographic anatomical markings as they emanated from the Darkroom. With the aid of a viewing box, the position of markers on the radiographs were sorted out into either primary or secondary radiation field using a tally sheet. Simple statistical tools were used to derive central tendency.

\section{Results}

623 radiographs were reviewed with $89.0 \%(\mathrm{n}=555)$ appearing within the primary radiation field while $11.0 \%$ $(n=68)$ appeared in the secondary radiation field. $98.0 \%(n=543)$ of those within the primary radiation field did not obstruct any essential anatomy while $2.0 \%(n=12)$ had some level of obstruction. Table 1 summarizes the findings.

Markers placed in the primary radiation field are sharp and aesthetic if placed on non-essential anatomy. In the event of burn-out due to over-penetration, they still appear legible. In the image of the proximal-half of right femur as shown in Figure 1, the marker was placed distally on the femur, a position that is non-essential anatomy to the investigation.

Although recommended that markers should be within the primary radiation field [4], this theory is flawed in the event of over-penetration as the marker is doomed to be burnt-out as shown in Figure 2. An extra-ordinary visual acuity or an abnormally high intensity of light from the viewing box would be needed to prove the presence of marker in the upper-left quadrant.

This marker was placed in the secondary radiation field and it appears very legible and aesthetic. The principle is to place it very close to the collimation line. The farther it is away from the line the more likely it is to become illegible or coned-off.

\section{Discussion}

Our findings show that radiographers in this centre habitually placed anatomical markers in the primary radiation field (Table 1). As deduced from the researchers' interaction with and observation of the radiographers, the fear of film reject due to marker ambiguity or absence was their guiding principle. This is quite commendable as film reject invariably leads to film repeat, and consequently, additional exposure to ionizing radiation with all its risks.

This practice is in tandem with the recommendation of Bontrager and Lampignano [4] as the risk of repeat from marker ambiguity is drastically reduced. Our findings however, revealed that the placement of markers in the primary radiation field did not offer any superiority to markers placed in the secondary radiation field except when placed on non-essential anatomy (Figures 1-3).

It was equally noted that an abnormally high density, which is likely in the primary radiation field, often masked markers, hence making the theory of Bontrager and Lampignano [4] not fool-proof. The work of Platt et $a l$. [5] however, is in tandem with our ambivalence on marker placement positions. 
Table 1. Radiation field characteristics of the radiographic anatomical markers.

\begin{tabular}{ccc}
\hline Radiation field & Obstructs essential anatomy & Nil obstruction of essential anatomy \\
\hline Primary & $12(2.0 \%)$ & $543(98.0 \%)$ \\
Secondary & 0 & $68(100.0 \%)$ \\
Total & $12(2.0 \%)$ & $611(98.0 \%)$ \\
\hline
\end{tabular}

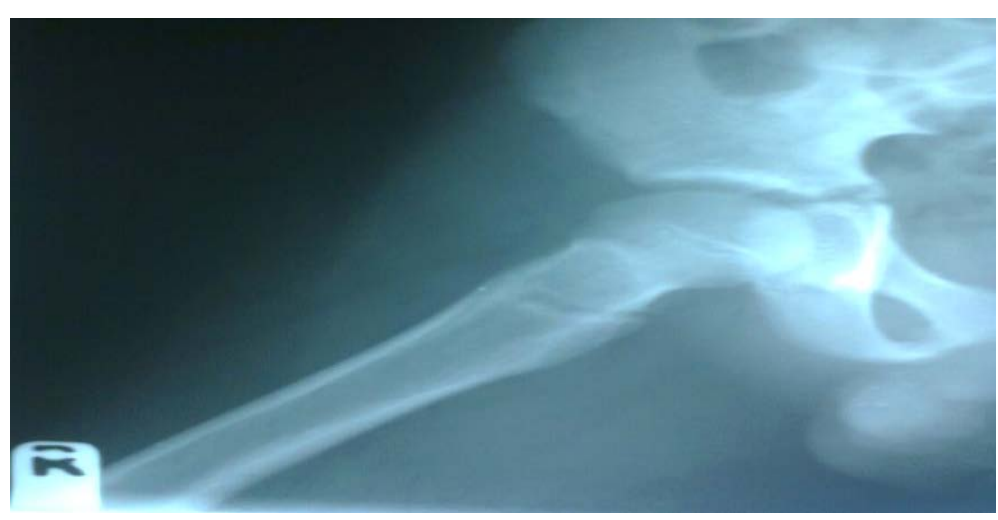

Figure 1. Marker within the primary radiation field with obstruction of nonessential anatomy.

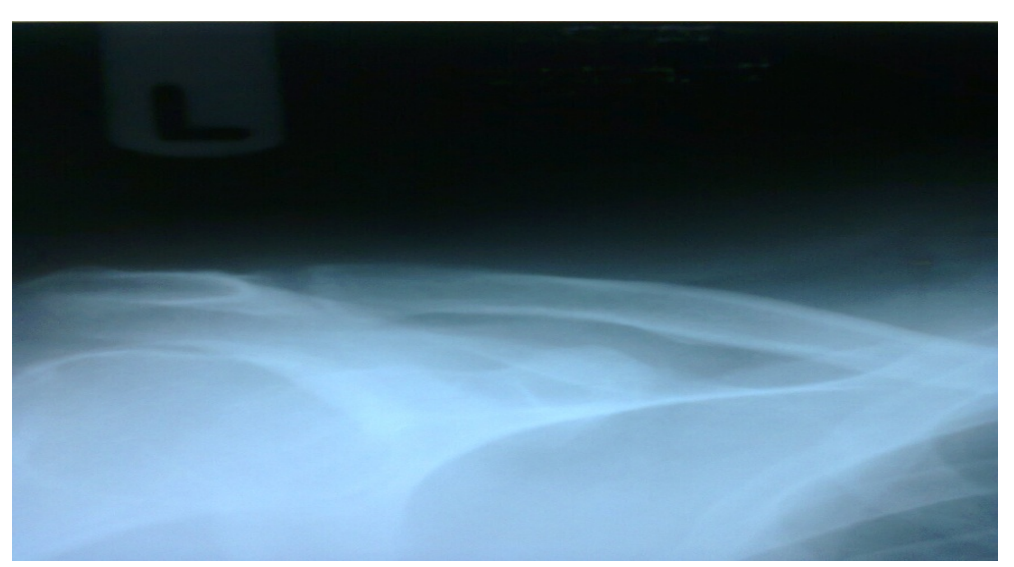

Figure 2. Marker within the primary radiation field free of anatomy.

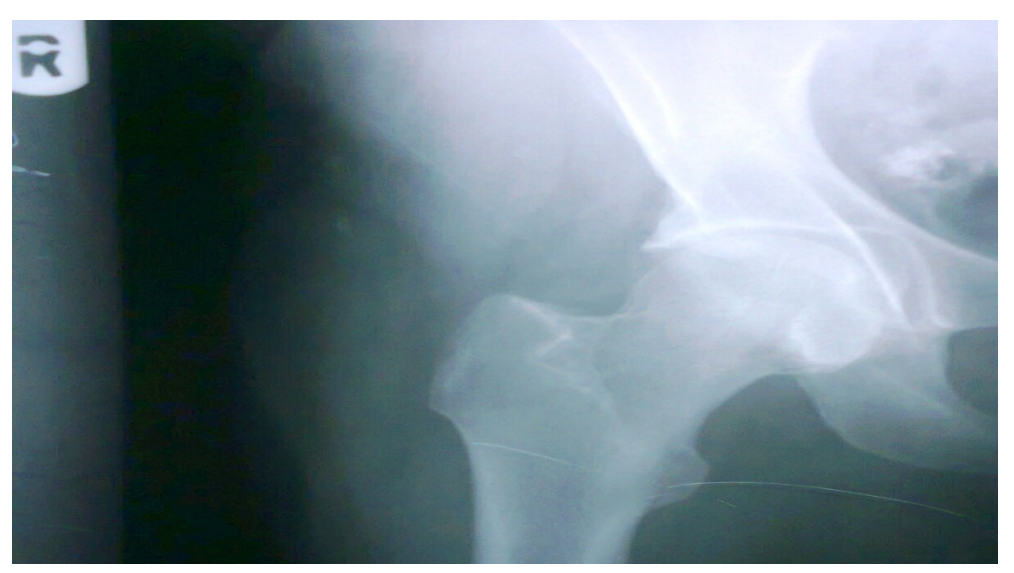

Figure 3. Marker placed in secondary radiation field. 
Our findings also revealed that markers placed in the secondary radiation field, very close to the collimation line, were clear and aesthetic like those in the primary field placed over non-essential anatomy. The major drawback here however, is the risk of marker cone-off and hence, repeat.

\section{Conclusion}

The authors are of the view that marker placement preference should be guided by the need for legibility, aesthetics and avoidance of essential anatomy. In the light of our findings, marker placement could be in the primary or secondary radiation field and still be considered adequate.

\section{References}

[1] Aakre, K.T. and Johnson, C.D. (2006) Plain-Radiographic Image Labeling: A Process to Improve Clinical Outcomes. Journal of American College of Radiologists, 3, 949-953. http://dx.doi.org/10.1016/j.jacr.2006.07.005

[2] Davis, M. and Reeves, P. (2004) Maintaining the Chain of Evidence in Child Abuse Cases. Journal of Diagnostic Radiology Imaging, 5, 61-68. http://dx.doi.org/10.1017/S1460472804000021

[3] Fabian, C.E. (2005) Knowing Right from Left on X-Rays: A Way to Minimize Errors of Laterality. Applied Radiology, 34, 19-22.

[4] Bontrager, K.L. and Lampignano, J.P. (2010) Textbook of Radiographic Positioning and Related Anatomy. 7th Edition, Mosby Elsevier, Maryland Heights, 30.

[5] Platt, J.M. and Strudwick, R.M. (2009) The Application of Anatomical Side Markers during Abdominal and IVU Examinations: An Investigation of Practice Prior to and Post-Installation of Computed Radiography (CR). Radiography, 15, 292-299. http://dx.doi.org/10.1016/j.radi.2008.11.006 
Scientific Research Publishing (SCIRP) is one of the largest Open Access journal publishers. It is currently publishing more than 200 open access, online, peer-reviewed journals covering a wide range of academic disciplines. SCIRP serves the worldwide academic communities and contributes to the progress and application of science with its publication.

Other selected journals from SCIRP are listed as below. Submit your manuscript to us via either submit@scirp.org or Online Submission Portal.
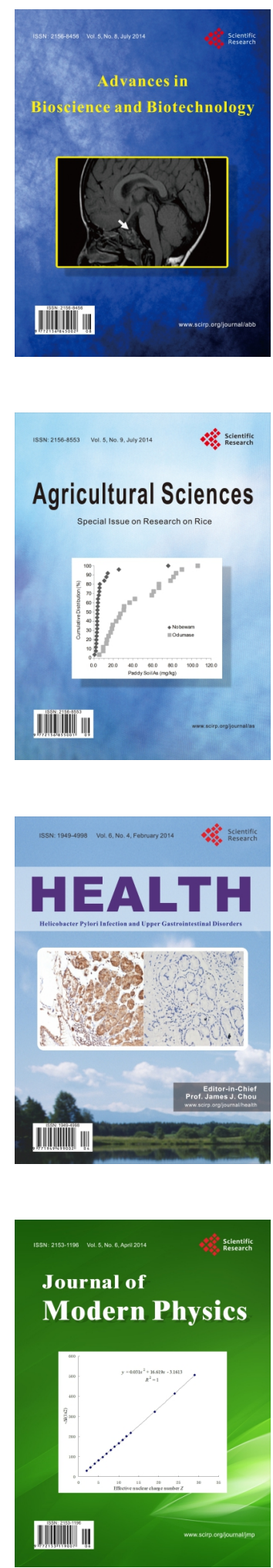
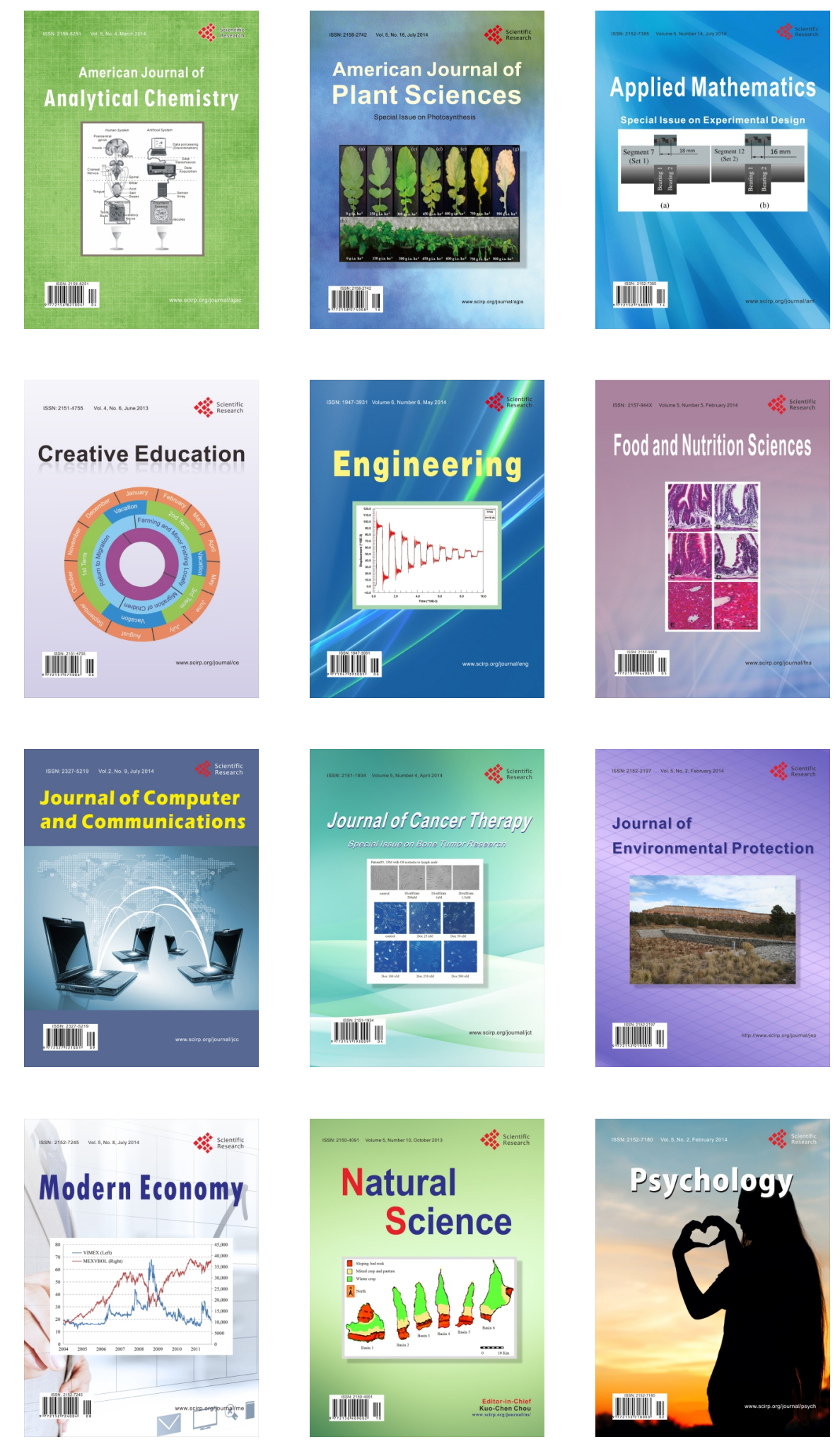